\title{
Repercussões do afastamento do trabalho na identidade de homens e mulheres - um estudo comparativo
}

\section{Repercussions of sick leave in the identity of men and women - a comparative study}

\author{
Thais Natal ${ }^{1}$, Carla Júlia Segre Faiman²
}

\begin{abstract}
Natal T, Faiman CJS. Repercussões do afastamento do trabalho na identidade de homens e mulheres - um estudo comparativo. Saúde, Ética \& Justiça. 2010;15(1)16-27.

RESUMO: O afastamento do trabalho exerce impacto importante na organização psíquica, repercutindo na identidade de quem se encontra nessa situação. O presente trabalho tem como objetivo compreender os efeitos do afastamento do trabalho decorrente de adoecimento na identidade de homens e de mulheres. Foi aplicada a técnica da História Oral Temática em oito trabalhadores, quatro homens e quatro mulheres, pacientes de um ambulatório de saúde do trabalhador. Diante do afastamento, os participantes mostraram sentimentos de inutilidade, inferioridade, perceberam-se doentes, com dificuldades de relacionamentos, impotentes diante das dificuldades, humilhados em decorrência das avaliações periciais necessárias para a obtenção de benefícios da Previdência Social, ansiosos com relação ao futuro. Concluiu-se que, na amostra estudada, com o afastamento, homens e mulheres sofreram importantes transformações na identidade. Homens apresentaram de forma mais marcante aspectos como tendência ao isolamento e sentimentos de humilhação. *Um pôster e um resumo do presente trabalho foram apresentados no VI Colóquio internacional de Psicodinâmica e Psicopatologia do Trabalho e I Congresso da Associação Internacional de Psicodinâmica e Psicopatologia do Trabalho, realizados de 21 a 23 de abril de 2010 em São Paulo.
\end{abstract}

DESCRITORES: Trabalho; Gênero; Identidade.

INTRODUÇÃO

$\mathrm{O}$ trabalho desempenha um papel central na vida das pessoas. Prover o sustento, proporcionar o convívio, o reconhecimento, possibilitar o estabelecimento de vínculos de amizade são alguns fatores que podem ser relacionados à atividade profissional. O trabalho pode também oferecer uma via privilegiada para a expressão subjetiva voltada para fins construtivos e favorecer o emprego e o desenvolvimento de habilidades.

O conceito "identidade" se refere ao que permite que cada um se reconheça e seja reconhecido, articulando semelhanças e diferenças'. Uma referência importante para a identidade, que pode ser tomada como exemplo para se pensar neste conceito, é o nome pessoal. O nome completo é uma articulação entre diferença (o nome próprio que é dado a cada um) e igualdade (o sobrenome

\footnotetext{
1 Psicóloga do Instituto de Pesquisas Tecnológicas do Estado de São Paulo S.A -IPT. Participou do Curso de Aprimoramento Saúde e Trabalho do Serviço de Saúde Ocupacional do Hospital das Clínicas da Faculdade de Medicina da USP.

2 Carla Júlia Segre Faiman - Psicóloga do Departamento de Medicina Legal, Ética Médica e Medicina Social e do Trabalho da Faculdade de Medicina da USP.

EndereÇO PARA CORRESPONDÊNCIA: Carla Júlia Segre Faiman. Faculdade de Medicina da Universidade de São Paulo - Instituto Oscar Freire. Avenida Doutor Arnaldo, 455 Cerqueira César, São Paulo/SP. CEP 01246-903. E-mail: cfaiman@uol.com.br/thais_natal@ ig.com.br
} 
que é comum a todos da família). Os papéis desempenhadosnacoletividade têmimportantepapel na construção da identidade e, nisso, destaca-se a atividade profissional desempenhada. A importância do trabalho para a identidade é discutida por diversos autores. Codo², observa que o trabalho...

“... é fonte de status, independência financeira e poder. É também um local de construção de uma rede social de apoio e de validação da competência relacional. Além de estar socialmente ligado à produção de bens e serviços, o trabalho constitui hoje fator importante de identidade e auto-estima, uma vez que a capacidade produtiva e a produtividade passaram a ser determinantes cruciais de valor pessoal e social" (p. 117).

Ciampa ${ }^{1}$ afirma que a identidade é constituída na ação que cada membro da comunidade desempenha. As pessoas são ativas, portanto, são também aquilo que fazem, bem como aquilo que já fizeram ou pretendem fazer. Daí a importância do trabalho de cada um.

Uma vez que a partir da diferença biológica dos sexos existem também diferenças sociais e culturais que influenciam a inserção social e a relação com o trabalho, a utilização da categoria gênero pode trazer elementos importantes para se compreender as relações entre trabalho e identidade.

Independentemente do sexo, como afirma Dejours $^{3}$, se o trabalho pode ser perigoso, é necessário compreender que o não-trabalho também pode sê-lo. São freqüentes as situações de afastamento devidas a prejuízos da saúde do trabalhador. Alguém acostumado a uma rotina de trabalho, quando se percebe sem a possibilidade de ir trabalhar, tem sua vida toda alterada. A inatividade pode provocar mudanças no âmbito social, no psíquico e no biológico. Assim, compreendendo a importância da atividade profissional na construção da identidade, infere-se que a situação de nãotrabalho também tenha suas repercussões.

Algumas Reflexões Referentes a identidade E TRABALHO

A formação da identidade é um processo contínuo e complexo, para o qual concorrem aspectos biológicos, psicológicos e sociais, em interação mútua. Ciampa ${ }^{1}$ destaca que a identidade é um fenômeno social, e não natural, e afirma que identidade é metamorfose, está em constante movimento. Transforma-se a si e ao mundo à sua volta. É nas relações que os membros do grupo estabelecem entre si e com o ambiente onde vivem, por meio do agir, que alguém se torna algo. O trabalho é uma via privilegiada para a realização humana, oferecendo um campo de atuação ao indivíduo e estabelecendo uma ligação entre a ação individual e o contexto social. Por meio do trabalho, a ação e seu autor podem ser reconhecidos. A identidade é uma espécie de composição em que diversos aspectos se formam e se manifestam como personagens. Quando não há possibilidade de assumir novas personagens, repetem-se as mesmas. Caso nem isso seja possível, caminha-se para a morte, seja ela biológica ou simbólica, o que pode resultar em doença. Resta ainda observar as possíveis diferenças do papel do trabalho para a identidade de homens e de mulheres.

IMPLICAÇÕES DO GÊNERO NO TRABALHO

Quando se fala em gênero, pensa-se na construção social e cultural sobre o sexo, que varia espacialmente (de uma cultura a outra), temporalmente (em uma mesma cultura há diferentes tempos históricos) e longitudinalmente (ao longo da vida de um indivíduo) Korin ${ }^{8}$. Já o termo sexo se restringe a um significado biológico. Por vezes, os significados construídos e atribuídos aos diferentes gêneros têm sido utilizados para justificar relações de poder entre homens e mulheres.

É possível pensar em uma série de características que diferenciam a mulher e o homem e acabam por influenciar a relação com o trabalho. Enquanto o homem produz hormônios que o impulsionam a assumir um comportamento mais agressivo, competitivo e territorial, a mulher passa por uma série de preparações em seu corpo em direção à gestação. Quando isso se dá, sua vida se altera completamente. Um bebê depende de seus pais, no entanto, é à mãe que cabe o exercício do aleitamento, o que a traz, muitas vezes, para as proximidades do lar e dos cuidados com os filhos, diferente do que ocorre com o homem que tende a contribuir de outros modos, como, por exemplo, mediante a provisão e sustento da família por meio 
Natal T, CJS Faiman. Repercussões do afastamento do trabalho na identidade de homens e mulheres

do trabalho. Logicamente, há que se considerar que a forma como homem e mulher se relacionam com o trabalho está em movimento e transformação incessante ao longo do tempo e do espaço, mas não se pode esquecer de atentar às diferenças existentes entre ambos que influenciam a vida de trabalho.

\section{O HOMEM E O TRABALHO}

Embora homens e mulheres atualmente tenham seus trabalhos e as funções de cada um sofram mudanças, ao homem ainda está fortemente atrelada à figura de provedor do lar, enquanto os cuidados com os filhos e com outros aspectos da casa recaem, comumente, sobre a mulher.

O trabalho é uma das vias em que o homem pode mostrar sua masculinidade e assegurar um lugar na sociedade. Por meio do trabalho, ele sente-se útil, desenvolve-se e pode trazer a provisão para sua família. Isso tem um impacto muito positivo em sua autoestima, na medida em que o faz sentir capaz, forte e corajoso. Sentimentos também presentes quando realiza alguma tarefa difícil ou perigosa. Afinal, quanto mais perigo estiver envolvido em um trabalho, mais são atribuídas coragem e virilidade àqueles que o desempenham.

\section{A MULHER E O TRABALHO}

Hoje, é comum que os dois cônjuges trabalhem fora em tempo integral, empreendendo pouco tempo com os papéis familiares. Essa dupla jornada de trabalho implica sobrecargas de papéis, sobretudo para as mulheres. "Assim, uma mulher trabalhar, casar, ter filhos, cuidar de si e zelar por sua saúde física e mental, vem se tornando tarefa cada vez mais complexa"4. Se, por um lado, o trabalho feminino é aceito e valorizado, por outro, é implícita a idéia de que o trabalho pode comprometer o exercício da maternidade.

Apesar das dificuldades impostas pela dupla jornada, Diniz ${ }^{4}$ aponta que o trabalho feminino impacta positivamente na autoestima, gerando gratificação e orgulho, além de favorecer o aspeto financeiro. Além disso, a vida doméstica muitas vezes é sentida como monótona e solitária. O trabalho pode, também, favorecer a construção de uma identidade própria, independente do marido e dos filhos, e aumentar o senso de competência. Há, contudo, mulheres que optam por não trabalhar fora e preferem se dedicar aos cuidados da casa e dos filhos, podendo realizar-se no desempenho destas funções.

Repercussões do afastamento nA IDENTIDAde DE TRABALHADORES E TRABALHADORAS

O afastamento pode ser entendido como um tempo em que um trabalhador acometido por um acidente ou doença deixa seu trabalho a fim de cuidar de sua saúde até que se restabeleça e retorne à sua função. Em afastamento, muitas vezes, o trabalhador sofre preconceito e recebe o rótulo de "trabalhador afastado", geralmente associado a desprestigio social, sentimentos de desvalia, de inutilidade e falta de perspectiva de futuro. Além do preconceito que podem sofrer, após acidente ou doença de trabalho, os trabalhadores percebemse com um corpo diferente, um corpo atravessado pelo adoecimento. Se não o corpo, a mente. Tudo isso pode ser acompanhado por dor e sofrimento.

Muitos autores entendem que a doença ocupacional e o acidente de trabalho carregam consigo mensagens que denunciam as condições de trabalho vigentes, simbolizando as tensões do jogo de forças entre empregados e empregadores, "É como se o indivíduo carregasse sem saber a bandeira de insatisfações que é de todos"5.

Quando o prejuízo à saúde que causa o afastamento pode ser relacionado ao trabalho, é comum, portanto, que esses trabalhadores gerem um desconforto no ambiente de trabalho e despertem desconfiança, principalmente da parte da chefia, quanto à veracidade ou não da doença, bem como de parte dos colegas que ficam com raiva, ou mesmo inveja, percebendo no afastamento uma condição de regalia, o que causa repercussões na identidade dos trabalhadores afastados. Rosin-Pinola, et al. ${ }^{9}$ consideram o acidente de trabalho como agente de ruptura da construção da identidade profissional, na medida em que todos os planos e expectativas individuais relacionados ao trabalho alteram-se consideravelmente.

Nesse sentido, um trabalhador que passa pelo afastamento terá sua identidade toda reformulada. Resta atentar às possíveis 
diferenças nos efeitos do afastamento na identidade de homens e de mulheres.

\section{Casuística e método}

Foram entrevistados oito trabalhadores afastados, à época, por mais de um ano, sendo quatro homens e quatro mulheres, pacientes de um ambulatório de saúde do trabalhador em São Paulo, portadores de doença relacionada ao trabalho. Utilizou-se o método de pesquisa de História Oral Temática que visa a dar voz a múltiplos e diferentes aspectos por meio da construção de uma narrativa da trajetória pessoal que tem como eixo um tema específico. O tema proposto foi a vivência do afastamento por doenças cujas causas relacionam-se ao trabalho. As entrevistas foram realizadas no ambulatório, tiveram duração de aproximadamente uma hora e foram gravadas em áudio para posterior transcrição. Para a publicação, os nomes dos entrevistados foram substituídos por outros para se preservar o sigilo. Os participantes colaboraram voluntariamente com a pesquisa, tendo lido e assinado o devido Termo de Consentimento. Para as entrevistas, utilizou-se o roteiro abaixo.
I - Apresentação:

Apresente-se do modo como desejar.

Conte-me quem é você.

\section{II - Trabalho:}

Conte-me como e quando começou a trabalhar.

Que atividades de trabalho já realizou?

Com quais trabalhos mais se identificou?

Em que mais gostava de trabalhar?

O que não gostava?

Como se sentia quando trabalhava?

Como era sua relação com a família e com os colegas de trabalho?

Como era sua rotina quando trabalhava?
III - Repercussões do afastamento:

Há quanto tempo está afastado?

Como se deu seu afastamento do trabalho?

Como você se sente após ter sido afastado?

O que mudou em sua vida após ter sido afastado do trabalho?

Como era sua saúde quando trabalhava, e agora com o afastamento?

Como está seu relacionamento com a família e amigos?

Quais são suas atividades após ter se afastado?

Qual é a sua rotina?

Quais são suas perspectivas, seus sonhos para o futuro?

Tabela 1 - Perfil dos trabalhadores entrevistados, afastados há mais de um ano, atendidos no ambulatório em 2008

\begin{tabular}{c|c|c|c|c|c|c}
\hline Nome & Idade & Estado Civil & Filhos & Escolaridade & Profissão & Tempo de afastamento \\
\hline José & 41 & Casado & 2 & Fundamental & $\begin{array}{c}\text { Cobrador } \\
\text { Motorista de ônibus }\end{array}$ & 2 anos \\
\hline Quirino & 50 & Casado & 2 & Médio & $\begin{array}{c}\text { Policial } \\
\text { Motorista de ônibus }\end{array}$ & 1 ano \\
\hline Adalberto & 45 & Casado & 2 & Médio/técnico & Ajudante de produção & $\begin{array}{c}\text { Atendente } \\
\text { Cobrador de ônibus }\end{array}$ \\
\hline Rafael & 54 & Casado & 1 & Fundamental & 8 anos \\
\hline
\end{tabular}

Tabela 2 - Perfil das trabalhadoras entrevistadas, afastadas há mais de ano, atendidas no ambulatório em 2008

\begin{tabular}{c|c|c|c|c|c|c}
\hline Nome & Idade & Estado Civil & Filhos & Escolaridade & Profissão & Tempo de afastamento \\
\hline Acidalia & 47 & Solteira & 0 & Médio & Demonstradora comercial & 2 anos \\
\hline Belmira & 30 & Casada & 2 & Médio & Operadora de telemarketing & 2 anos \\
\hline Cassiana & 56 & Viúva & 2 & $\begin{array}{c}\text { Fundamental } \\
\text { incompleto }\end{array}$ & $\begin{array}{c}\text { Costureira } \\
\text { Modelista }\end{array}$ \\
\hline Ofélia & 43 & Solteira & 2 & Médio & Cobradora de ônibus & 4 anos \\
\hline
\end{tabular}


Natal T, CJS Faiman. Repercussões do afastamento do trabalho na identidade de homens e mulheres

Um trabalhador acometido por doença ou acidente de trabalho que precise afastar-se tem sua identidade rearranjada. De acordo com Ciampa ${ }^{1}$, não há um momento em que se encerra a formação da identidade. Enquanto há vida, ela se modifica continuamente, o que não é diferente quando se tem a vida atravessada por um afastamento.

Segundo o mesmo autor, ao tentar traçar a identidade de uma pessoa, recorremos a diversas instâncias a fim de tentar responder a pergunta "Quem é você?". Portanto, ao tentar refletir sobre a identidade dos trabalhadores afastados, optouse por recorrer a algumas dessas instâncias. Primeiramente, procurou-se avaliar como os trabalhadores se apresentaram, em seguida, como atualmente percebem sua identidade no tempo em que trabalhavam, e, por fim, como se percebem como trabalhadores afastados.

Quem SOU EU? - A APRESENTAÇÃo DE TRABALHADORES E TRABALHADORAS AFASTADOS

$\mathrm{Na}$ primeira etapa da entrevista, os entrevistados foram convidados a apresentarse livremente, da maneira como desejassem. Constatou-se, nas entrevistas realizadas, que a maioria dos entrevistados, tanto homens como mulheres, forneceu seus nomes para se apresentar, e, em seguida, os homens fizeram menção a seu trabalho e trataram direta ou indiretamente da questão do afastamento, ao passo que somente uma mulher falou de sua ocupação. As demais, abordaram aspectos referentes à família, ao número de filhos que têm, ao seu estado civil, que são assuntos também abordados pelos homens. De acordo com Diniz ${ }^{4}$, os homens têm se achegado mais à família, desenvolvendo outras prioridades além do trabalho e, segundo esse autor, tais mudanças podem implicar alterações no que tange à autoestima, pois, até então, a autoestima do homem sempre esteve ligada ao desempenho profissional. Isso pode indicar que o tempo de afastamento corrobore para que o homem descubra novos interesses e se identifique com outras questões que não somente o trabalho, podendo investir maior atenção na família, por exemplo.
EU ERA ASSIM QUANDO TRABALHAVA: PERCEPÇÕES ATUAIS DOS TRABALHADORES AFASTADOS SOBRE SUAS VIDAS COM TRABALHO

Com relação aos seus trabalhos, homens e mulheres parecem considerar suas funções importantes e demonstram que se sentiam úteis ao desempenhá-las.

O trabalho aparece para homens e mulheres como um espaço repleto de desafios que propicia crescimento, superação e amadurecimento, o que repercute diretamente na autoestima dos trabalhadores. Por meio do trabalho, os trabalhadores podem se sentir necessários, importantes, úteis, habilidosos e reconhecidos.

O ambiente de trabalho também é o local em que se dão os relacionamentos. De acordo com Ciampa ${ }^{1}$, é também a partir dos relacionamentos que a identidade se constitui, afinal, a partir das interações entre as pessoas é que elas vão se constituindo umas as outras. As mulheres lembram-se positivamente dos relacionamentos no trabalho. Lá elas ajudavam os demais colegas e eram por eles ajudadas. Também os homens comentam sobre seus relacionamentos no tempo do trabalho. Todavia, não são tão enfáticos quanto as mulheres nesse ponto. Mencionam o convívio no trabalho, mas com certo distanciamento.

O fato de o trabalho ocupar a maior parte do dia parece repercutir na identidade, sobretudo das mulheres, que precisam equilibrar-se mediante as demandas do trabalho e dos cuidados com a casa e com a família. Trata-se da conhecida "dupla-jornada de trabalho", que representa uma sobrecarga acentuada. Muitas vezes a mulher não consegue desempenhar todas essas funções da maneira que gostaria, o que a faz sentir-se culpada.

Na fala dos homens, não há indícios de queixas voltadas à dupla-jornada de trabalho, mas é presente a queixa de sobrecarga de trabalho que comprometia seus relacionamentos em casa e sua saúde. Por causa do trabalho pesado, esses homens chegavam em casa e sentiam-se sem energia para investir na família. A sobrecarga do trabalho propriamente dita também é presente na fala das mulheres.

Observa-se que o trabalho pode repercutir no processo de constituição de identidade do 
trabalhador compondo a sua autoimagem tanto com aspectos favoráveis como com aspectos desfavoráveis. A sobrecarga no trabalho traz consigo o cansaço, o desgaste, o desânimo, desmotivação, além de sentimentos de impotência. O próprio adoecimento e o comprometimento dos relacionamentos podem serdecorrentes do trabalho e se refletem na identidade do trabalhador.

O trabalho e aspectos de sua organização podem gerar frustração e favorecer o adoecimento. Condições precárias de trabalho, desvalorização dos funcionários, falta de reconhecimento, necessidade de romper com os valores pessoais a fim de dar conta das demandas requeridas pela empresa, são alguns exemplos de situações geradoras de sofrimento.

São muitas as razões pelas quais o trabalho pode ser elemento de saúde ou doença. No entanto, tendo visto seu papel como um dos elementos importantes no processo de constituição da identidade, é necessário voltar-se agora às implicações do afastamento na identidade de trabalhadores e trabalhadoras.

Quem eU ME TORNEI DEPOIS DE TER ME AFAstado DO tRABalho: O AfASTAMENTO E SEUS EFEITOS NA IDENTIDADE DE HOMENS E DE MULHERES.

Todos os trabalhadores que antes ocupavam grande parte dos seus dias no trabalho, ao afastarem-se, seja por doença ou acidente relacionados ou não ao trabalho, têm suas vidas completamente modificadas e conseqüentemente sua identidade rearranjada. A começar por seus corpos. Após doença ou acidente, os trabalhadores percebem-se com um corpo diferente, limitado, marcado pela dor.

Como pode ser visto em uma das entrevistadas que enfrentou uma série de adaptações por conta das mudanças em seu corpo. Antes, era ativa no preparo dos alimentos, cortava, segurava, picava... Agora, não consegue mais realizar essas atividades o que lhe traz sentimentos de irritação, impotência e inutilidade. Diante disso, resta encontrar saídas para adaptar-se ao seu novo corpo. Isso vem confirmar o que Gaedke e Krug ${ }^{6}$ dizem sobre os efeitos do afastamento em mulheres:

"Estas dificuldades fazem com que as mulheres se sintam angustiadas e nervosas, tendo que encontrar formas de se adaptar a essa nova realidade, já que em algumas situações não há quem possa auxiliá-las"

Além disso, por conta das doenças, a ingestão de uma série de medicamentos pode acarretar mudanças no corpo e abalar a auto-estima das mulheres.

Os homens também comentam as mudanças em seus corpos:

"Eu não guento ficar de pé, uma hora.... se eu ficar de pé uma hora eu caio. Eu não tenho força, começa a queimar o meu corpo, braço , perna... o corpo inteiro... a coluna começa a queimar, o braço em cima... vai cansando, vai cansando, vai queimando... tem uma hora que eu tenho que sentar, aí eu fico sentado até que alivia... e assim eu vou vivendo... (...)" Rafael

Infere-se daí que a dificuldade em encontrar uma posição na qual ele se sinta bem vai além da posição do corpo. Parece que, por estar afastado, não encontra um lugar para si perante a sociedade. Ele que está sem receber os benefícios do INSS, sem poder sustentar sua família, impossibilitado de ir trabalhar, parece sentir-se sem rumo, sem posição como mostra Jimenez ${ }^{7}$ :

"Para o homem a perda do emprego não é apenas a perda de dinheiro no fim do mês, mas a perda de um lugar na rede social e de uma identidade associada a esse lugar".

Tanto as mulheres como os homens percebemse não somente com um corpo diferente, mas também com a saúde mental comprometida. Seja qual for o transtorno, homens e mulheres falam de comprometimentos em sua saúde mental carregados de muito sofrimento. Diante disso, precisam ir em busca de tratamentos médicos a fim de cuidar da saúde, o que ocupa grande parte de suas rotinas.

Diversos são os tratamentos médicos a que se submetem, muitos também são os medicamentos que ingerem. Longe do trabalho, os trabalhadores afastados tornam-se pacientes, passam a ocupar seu tempo consigo mesmos, com suas doenças, com seus tratamentos. Os cuidados com a saúde passam a ser um objetivo de vida, compondo, 
muitas vezes, uma "identidade de doente".

Os assuntos relacionados aos benefícios previdenciários que garantem o sustento e, portanto, ao INSS, órgão que concede os benefícios previdenciários e realiza avaliações periciais para definir se o trabalhador apresenta condições para trabalhar ou, ao contrário, está doente e faz jus ao benefício, mobilizam tempo e preocupação desses trabalhadores. Ocorre, por vezes, de o trabalhador não poder ainda retornar ao trabalho devido à sua saúde e, mesmo assim, não receber ou deixar de receber o auxílio financeiro do INSS.

As mulheres mostraram-se bastante aflitas e desamparadas devido às dificuldades financeiras em tempos de afastamento. Com relação aos homens, somente um dos entrevistados reclamou das dificuldades financeiras em tempo de afastamento. Os demais alegam não terem sofrido problemas com o INSS em se tratando de aspectos financeiros. Para os homens entrevistados, além da preocupação pelo fato de depender da avaliação pericial do INSS, estar sem o benefício, os remete a uma situação constrangedora por virem a depender de outras pessoas para o sustento.

"Aí minha filha cresceu agora, ela arrumou um marido, que é meu genro que ta com ela, com a minha filha. E ele ta assumindo as contas de casa e botando arroz e feijão dentro de casa pra comer. (...) Só que eu me sinto assim, uma pessoa muito... eu não quer ser assim, sobreviver assim às custas da minha filha, do meu genro... eu queria ter o meu salário, pra mim sobreviver eu e a mulher, sem depender nem de filho, nem de genro, nem de ninguém... mas infelizmente eu tenho que depender (...) Até quando eu vou depender da minha filha? (...) Eu quase me mato..." Rafael.

É como se o homem perdesse o controle que antes usufruía quando era o responsável por arcar com suas obrigações de chefe de família. Agora, ao depender de outros, sente-se desprovido do seu papel, atingido naquilo que o faz homem e em sua identidade social. A vida parece não ter sentido e fica muito difícil de suportar, podendo até mesmo pensar-se em desistir da própria vida.

Por terem contribuído boa parte de suas vidas com o INSS, quando ocorre de, na doença, terem seus benefícios negados, homens e mulheres se sentem injustiçados.

"Tanto que eu trabalhei! (...) Trabalhei, paguei o INSS, durou 30 anos. Trinta anos de contribuição. Quer dizer... pelo meu problema de saúde que eu tenho... que eu preciso... eu acho que o INSS tá fazendo uma injustiça comigo, comigo e com muitos iguais a eu" Rafael

Sobre a perícia (avaliação realizada por médico do INSS), dizem sentir-se incompreendidos e desrespeitados pelos médicos que os atendem. Afirmam também se sentirem cansados de terem que constantemente ir atrás de novos laudos e remarcar a perícia, por terem tido seus benefícios negados. Isso tudo gera muita frustração e sentimentos de humilhação:

“(...) o primeiro médico que eu peguei me tratou pior do que um cachorro. Parecia que eu tinha uma doença contagiosa, porque nem perto de mim ele quis chegar (...) Aí você se sente abandonado, largado. Se você já está ruim, você fica pior. É o que acontece. E eles não estão nem aí”. Belmira

Ao passar pela perícia (avaliação de médicoperito do INSS), os trabalhadores afastados se sentem humilhados e desrespeitados. Como, em muitos casos, os sintomas da doença não são aparentes, pode ocorrer de o perito desconfiar da veracidade ou das limitações impostas pela doença. Diante de tantas desconfianças, é possível até mesmo que os próprios trabalhadores passem a duvidar da veracidade de suas doenças.

"O sujeito acaba por introjetar as desconfianças do ambiente e, assim, precisa reafirmar não só para outro, mas sobretudo para si, a veracidade da própria doença (...) O sujeito adoece por pressão, ameaça e, além disso, carrega um forte sentimento de culpa" (p. 38$)^{5}$.

A tensão envolvida no relacionamento interpessoal dos afastados, não se restringe às perícias, uma vez que demonstram também incômodo pela forma como acreditam serem vistos pelas pessoas em geral.

"Porque a gente se sente um nada. Eu falei pra você. As pessoas olham pra você. Tá no seguro, é vagabundo. Ó, imagina, ó a cara dela, ta boa, não 
quer trabalhar. Imagina... mentira.... olha isso aí é a pior coisa do mundo. Acredito que isso não acontece só comigo, acontece com tudo mundo." Aciália

Tudo isso contribui para que se sintam solitários e desamparados. Ciampa ${ }^{1}$ diz que é no relacionamento que se trava entre as pessoas que a identidade também se constitui. Em tempos de afastamento, a pessoa não se afasta somente do trabalho, mas se afasta também dos colegas de atividade e, muitas vezes, da sociedade em geral. Muitos afastados tendem a isolar-se e a ter dificuldades para desenvolver relacionamentos.

"Mas o pior em estar afastada é... que eu me sinto fora da sociedade. Sabe quando você anda na rua... e ver... eu passo por aqui e sinto inveja às vezes... todo mundo tá de branco ou todo mundo tá entrando, indo nas suas atividades... fazendo...e lembro de mim, de uniforme, com as minhas colegas conversando. "Ou... vai ter décimo terceiro! Vamos fazer festa, vamos se reunir... tal coisa!" A gente se sente isolada... eu acho que todo mundo que passa por isso se sente sozinho. Porque em casa você não tem a colega de doença". Acidália.

Em se tratando do relacionamento com a família, alguns homens parecem ter tido seus relacionamentos com suas esposas abalados após se afastarem:

"Fui discriminado tanto na empresa quanto na minha casa. Tive que passar por uma separação. A ponto da minha esposa achar que eu passava produto químico pra ela, o que não tinha nada a ver". Adalberto.

"Dentro de casa, o meu relacionamento abalou um pouco, ta meio que abalado. A gente não tem mais quase relacionamento de homem e mulher, mudou essas coisas de afinidade e de procura. Já vinha acontecendo num processo mais lento, mas depois do afastamento isso deu uma piorada." José.

Ao se verem impossibilitados de arcar com suas responsabilidades, ou mesmo de gozarem do reconhecimento no trabalho e de sentirem-se úteis, os homem parecem tender a sentir-se abalados em sua virilidade, masculinidade e, conseqüentemente, em sua auto-estima, com dificuldades em exercer seu papel de homem, principalmente quando se encontram dependentes de outros para arcar com as responsabilidade que outrora eram suas, dependendo muitas vezes da esposa. Isso pode acabar gerando conflitos familiares.

Seja pelas desconfianças, preconceito, humilhação, desrespeito, saúde comprometida, dificuldades financeiras, relacionamentos conflituosos e demais adversidades comuns a quem se encontra afastado, homens e mulheres tendem a apresentar sentimentos de raiva e hostilidade e consequente temor diante de sua agressividade interna. Assustam-se com o desejo de reação violenta diante do outro, ou mesmo de matar.

Além da agressividade dirigida ao outro, é presente também a agressividade dirigida a si mesmo diante do desespero. Não é incomum terem pensamentos destrutivos em que cogitam acabar com a própria vida.

Como forma de reagir aos percalços do afastamento, homens e mulheres encontram estratégias para lidar com o afastamento. É importante pensar no que fazem os trabalhadores afastados quando se busca entender sobre sua identidade. Em suas vidas de afastadas, as mulheres adotaram rotinas diferentes para si: cuidar da casa, reaproximar-se da família, tornarse cuidadora de algum membro doente da família. Isso vem a confirmar o que diz Jimenez ${ }^{7}$, quando fala que a mulher tende a ter sua identidade social preservada ao ser impedida de trabalhar. Afinal, ela pode exercer atividades que lhe trazem prestígio junto à sociedade, bem como prazer. Tarefas consideradas apropriadas ao feminino, como o cuidado com o lar e com a família. Como também atividades fora de casa, como estudar, fazer artesanato, vender camisetas...

Com relação à rotina dos homens, observase tendência ao isolamento. Aproximação do lar como uma forma de se proteger de uma sociedade hostil onde eles não encontram mais lugar.

"Eu criei um mundo pra mim, o meu mundo (...) aonde eu sou respeitado, é um mundo aonde eu posso falar, é um mundo aonde eu sou compreendido, é um mundo aonde as pessoas me conhecem. É um mundo bom, maravilhoso, que é dentro da minha casa (...) Eu vivo dentro da minha casa, eu não 
Natal T, CJS Faiman. Repercussões do afastamento do trabalho na identidade de homens e mulheres

tenho prazer nenhum em sair. Eu tenho meus dois filhos que me cobram pra eu ir no cinema, pra mim sair com eles, eu to sempre dando uma desculpa. Eu não saio, é muito raro, é difícil". José

Parece que os homens se sentem envergonhados por não estarem trabalhando. Sentem-se sem lugar na sociedade, percebem-se inúteis como homens. Abalados em sua virilidade e masculinidade, feridos em sua identidade social de provedor e de trabalhador. Daí o isolamento, o fechar as portas para o mundo e o mergulho em um mundo particular.

Afastados de seus trabalhos, os trabalhadores dizem sentir-se inúteis e improdutivos:

"Eu, principalmente, preciso me sentir útil, valorizado. É bom quando você... poxa vida! Tem um trabalho... "Você trabalha onde?" Trabalha em tal lugar. Sai cedo de casa, faz sua obrigação, volta pra casa. Então, ou seja, viver a vida!" José.

Diante dessa realidade, os homens tendem a buscar estratégias para voltar a achar um lugar para si e sentir-se útil. Aproximar-se das tarefas domésticas, fazer reparos e consertos, e também vender algo. $\mathrm{O}$ afastamento pode também propiciar que se redescubra e fortaleça o papel de pai.

"E hoje não, hoje eu fico dentro da minha casa, acompanho os meus filhos... a criação, a educação, orientação. Eu to mais um pai presente, eu to mais ali. Então, se eu morrer hoje, eu posso dizer que eu acompanhei um pouco do crescimento dos meus filhos". José .

Pode ainda ser um tempo de despertar para novas atividades, como envolver-se em cursos, palestras, terapias de grupo, bem como em práticas esportivas, viagens, atividades que parecem contribuir com a saúde mental dos afastados.

O fato é que, ainda que se envolvam em atividades e se despertem a novos interesses, a maioria dos trabalhadores, independente do sexo, parece ter vontade de retornar ao trabalho:

"Eu sinto vontade de ir trabalhar, de ocupar minha cabeça... gostaria de levantar cedinho, igual eu levantava sempre, ir pro meu trabalho, ter o que fazer.... chegar no fim do mês e ter minha recompensa, pagar minhas contas... Se eu pudesse voltar a trabalhar eu estaria melhor do que hoje. Hoje eu me sinto mais doente parada em casa". Cassiana.

"Eu não tô me sentindo muito bem... porque eu gostaria que a minha vida não fosse assim. Eu gostaria de estar fazendo alguma coisa, me sentindo útil”. José.

Enfraquecimento, engorda, dor, desconforto com efeitos colaterais de remédios foram associados ao período de afastamento nos relatos, assim como desânimo, irritabilidade e falta de vontade de viver. Duas das mulheres entrevistadas assumiram o papel de cuidadoras, seja de filhos ou de pais. Uma das entrevistadas referiu satisfação com a condição de afastamento. Entre os homens, o isolamento social ea dificuldade de preencher o tempo ocioso aparecem de forma importante. Homens e mulheres referem vontade de trabalhar e insegurança quanto ao eventual retorno. Sentimentos de exclusão social também são presentes.

A instituição de saúde foi citada por alguns dos pacientes como um espaço de inserção social ao propiciar o contato com os profissionais de saúde e com outros pacientes em situação semelhante. A interação que ocorre entre pacientes do ambulatório foi citada como uma possibilidade de construção de laços de identificação que atenuam a eventual solidão e a falta de referências pessoais decorrentes do afastamento. Os profissionais de saúde são citados como importantes colaboradores para a superação das dificuldades.

Os participantes relataram, ainda, sentiremse humilhados e desrespeitados nas avaliações periciais do INSS e na necessidade de provaremse doentes para conseguir o benefício social.

A vontade de voltar ao trabalho denota o quanto o trabalho ocupa um lugar importante na vida de homens e mulheres. Entretanto, ainda que tenham vontade de voltar ao trabalho, sentem-se inseguros quanto ao retorno. Seja por não se perceberem com condições de saúde para dar conta do trabalho, ou mesmo por receio de regressar à empresa.

Apesar da falta de perspectiva quanto ao futuro, é possível sonhar. Ciampa ${ }^{1}$ diz que, ao 
se pensar sobre a identidade de uma pessoa, é necessário compreender seu presente, passado e futuro. Mas como falar sobre futuro se ele ainda não aconteceu? O autor afirma que é possível pensar no amanhã quando se fala de sonhos. Os sonhos de homens e mulheres se mostraram muito semelhantes. Em alguns, há o desejo de voltar a trabalhar, em outros, a vontade de recuperar a saúde e continuar fazendo os tratamentos. Outros esperam poder dar melhores condições para seus filhos e para a família. Há quem fale da vontade de aprender novas ocupações mediante oficinas, cursos e oportunidades.

Se há nos sonhos vontade de trabalhar, há também vontade de parar. A aposentadoria é um desejo de alguns. Esse desejo de não mais trabalhar também se reflete na vontade de sair da cidade de São Paulo e viajar para um lugar mais tranqüilo ou de origem, onde se imagina poder sair da confusão e ter mais tranqüilidade.

Ciampa ${ }^{1}$ diz que à medida que um indivíduo concilia seu desejo com a finalidade no agir, transforma a si e também ao mundo. Há unidade da subjetividade e objetividade, resultando em uma prática transformadora de si e do mundo. Afinal, enquanto há sonhos, há vida.

\section{ConClusões E CONSIDERAÇÕES FINAIS}

Quando um trabalhador é afastado de seu trabalho não é mais o mesmo, tem sua identidade toda rearranjada. Os efeitos do afastamento na identidade de homens e de mulheres são bastante semelhantes, diferindo somente em algumas peculiaridades.

Independente do gênero, ambos se percebem enfermos, seja física ou mentalmente, podendo assumir a identidade de paciente ou mesmo de doente. Sentem-sehumilhadoseincompreendidos diante das perícias médicas e da sociedade, vítimas de preconceito e de julgamentos. Ansiosos e temerosos com relação ao futuro. Inúteis e com a auto-estima rebaixada.

As mulheres podem ter esses sentimentos atenuados e obter prazer e reconhecimento, ao aproximar-se do papel de mãe e de dona de casa, o que não ocorre quando sentem-se impedidas de desempenhá-lo em decorrência de limitações físicas ou emocionais, gerando sentimentos de frustração e irritação. Também os homens podem beneficiar-se ao se aproximar mais dos filhos e dos cuidados com o lar, porém parecem sentirse envergonhados e destituídos de um lugar, acabando por isolar-se da sociedade.

Constata-se, portanto, que os trabalhadores afastados são atravessados por transformações nos âmbitos biopsicossociais, na medida em que se sentem doentes, fragilizados emocionalmente e com dificuldades de cultivar relacionamentos. Muitos se sentem irritados e desmotivados, ou mesmo receosos diante da própria violência interna alimentada pela frustração e pelos sentimentos de impotência. Os homens mencionam comprometimentos em seus relacionamentos conjugais após o afastamento.

Homens e mulheres falam da expectativa de ter a saúde restabelecida, de dar continuidade aos seus tratamentos, também referem desejo de se aposentar e de sair de São Paulo. Por outro lado, há também o desejo de retornar ao trabalho, o que reafirma a importância do trabalho como elemento para a saúde e para a constituição da identidade.

A vida com trabalho aparece como fonte de doença ou de saúde. Por um lado, dependendo das condições e da organização do trabalho, traz consigo o cansaço, a sobrecarga, ressentimento e desmotivação, bem como comprometimentos na auto-estima e na vida social, ou mesmo, o adoecimento. Por outro lado, mostra-se repleta de desafios, superações, desenvolvimento, aprendizagem, relacionamentos, além de propiciar o sustento. Já a vida sem trabalho, decorrente do afastamento, consiste em consultas e tratamentos médicos, ingestão de remédios, convívio intenso com profissionais de saúde, perícias médicas, assim como permanecer em casa ou buscar, nem sempre com sucesso, envolvimento em outras atividades, quer hobbies, esportes, artesanato, cursos ou mesmo "bicos" a fim de sentir-se útil. Afinal, longe do trabalho, homens e mulheres percebem-se desorientados e inúteis, ao passo que, ao trabalhar, sentem-se com uma missão a cumprir.

Dentre os trabalhadores afastados, homens ou mulheres, muitos sofrem com a condição de afastamento e percebem que se beneficiariam caso conseguissem reinserção no mercado. 
Natal T, CJS Faiman. Repercussões do afastamento do trabalho na identidade de homens e mulheres

Desejam trabalhar, mas lutam pelo prolongamento do benefício por não se encontrarem aptos a retornar às suas funções. Seqüelas físicas ou dificuldades psíquicas, ou, ainda, a combinação de ambas, quando não impedem, dificultam muito o retorno. A aplicação da proposta de realocar o trabalhador que retorna do afastamento em função compatível com a sua possibilidade, levando em conta o seu adoecimento, raramente encontra respaldo nas condições reais dentro das empresas. $\mathrm{E}$, considerando o presente contexto social, no qual as taxas de desemprego ilustram a dificuldade de inserção dos trabalhadores, aventurar-se a procurar outro trabalho, tendo desenvolvido algum distúrbio, geralmente, não é alternativa que se coloque. Assim, é absolutamente compreensível que se tente prolongar o benefício que, ao menos, garante o sustento.

Entre os aspectos que compõem a vivência do trabalhador em afastamento, no que se refere à sua perspectiva de reinserção, podem-se destacar as dificuldades vividas no âmbito do trabalho, por vezes relacionadas às causas afastamento, acrescidas das perdas relacionadas aos processos de adoecimento, da incerteza quanto ao retorno e às próprias capacidades, das dificuldades econômicas e da eventual humilhação social, que acomete principalmente os homens, que podem se sentir considerados como "vagabundos".

A dificuldade para um desfecho favorável da situação descrita, levando em conta aspectos diversos e por vezes conflitantes, geralmente exerce uma pressão no sentido da cronificação do adoecimento, uma vez que as necessidades básicas de sobrevivência, que podem ser supridas pelo benefício do INSS, representam, naturalmente, um forte apelo. É, portanto, necessário que se pense em políticas públicas voltadas a esta questão. Políticas que visem à saúde e à reabilitação desses trabalhadores.

Natal T, Faiman CJS. Effects of sick leave on the identity of men and women - a comparative study. Saúde, Ética \& Justiça. 2010;15(1):16-27.

AвSTRACT: Sick leave may result in a great impact on psychological organizaton, affecting the identity of those who are in this condition. The scope of this study is to understand the effects of such removal on the identity of men and women. A technique in which people are invited to tell their stories through open question about specific issues (thematic oral storytelling) was used in eight patients (four men and four women) at a health clinic for workers. Facing the removal, the volunteers reported feelings of worthlessness, inferiority, sickness, stress in dealing with relationships, vulnerability facing difficulties, humiliation due to medical evaluation of their work capacities and rights to receive sick leave benefits and anxiety about the future. Through this sample it was concluded that being removed makes men and women suffer and experience important changes in their identity. Men present strong tendencies to cer tain behavior such as isolation and humiliation feelings.

KEYWORDS: Work; Gender; Identity.

REFERÊNCIAS

1. Ciampa AC. A estória do Severino e a história da Severina. São Paulo: Brasiliense; 1998.

2. Codo W. O trabalho enlouquece? Um encontro entre a clínica e o trabalho. Petrópolis: Vozes; 2004.
3. Dejours C. Por um novo conceito de saúde. Rev Bras Saúde Ocup 1986;14(54):7-11.

4. Diniz G. Mulher, trabalho e saúde mental. In: Codo W. O trabalho enlouquece? Um encontro entre a clínica e o trabalho. Petrópolis: Vozes; 2004. 
Natal T, CJS Faiman. Repercussões do afastamento do trabalho na identidade de homens e mulheres

5. Durand M. Doença ocupacional: psicanálise e relações de trabalho. São Paulo: Escuta; 2000.

6. Gaedke MA, Krug SBF. Quem eu sou? A identidade de trabalhadoras portadoras de LER/DORT. Rev Textos. 2008;7(1):120-37.

7. Jimenez L. Efeitos do desemprego prolongado na divisão sexual do trabalho: estudo de uma população masculina do ABC - São Paulo, SP,
[Dissertação]. São Paulo: Departamento de Saúde Pública da Universidade de São Paulo; 2002.

8. Korin D. Novas perspectivas de gênero em saúde. Rev Adolesc Latinoam. 2001;2(2):67-79.

9. Rosin-Pinola AR, Silva CP, Garbulho NF. Implicações psicossociais para o acidentado de trabalho reinserido no mercado de trabalho e desempregado. Rev Bras Orientac Prof [citado 27 nov. 2008]. 2004;5(2):53-62.

Recebido em: 08/04/2010

Aprovado em: 10/05/2010 